\title{
Identification, Characterization and Evaluation of Crystal Forms of Quinine Sulphate
}

\author{
Maninder Karan*, Renu Chadha, Kunal Chadha, Poonam Arora
}

University Institute of Pharmaceutical Sciences, Panjab University, Chandigarh, India.

Email: *maninderkaran@hotmail.com

Received January $14^{\text {th }}, 2012$; revised February $17^{\text {th }}, 2012$; accepted March $5^{\text {th }}, 2012$

\begin{abstract}
Crystal engineering concept has been utilized to modify the physico-chemical parameters of a naturally occurring alkaloid, quinine sulphate, by exploring its H-bond interactions to generate different forms. Quinine sulphate is found to exist in four different crystal forms. The Forms I and II depict endo/exo events suggesting conversion of metastable low melting forms to higher melting and stable form indicated by sharp melting endotherms. The low melting form $\mathrm{I}_{\mathrm{L}}$ is found to be monotropically related to high melting Form $\mathrm{I}_{\mathrm{H}}$ while low melting Form $\mathrm{II}_{\mathrm{L}}$ is enantiotropically related to high melting Form $\mathrm{II}_{\mathrm{H}}$. The Form III and IV showed broad endotherms accompanied by mass loss in TGA prior to melting indicating the existence of solvatomorphism. The solvent molecules are tightly bound in the crystal lattice of the drug molecules which is shown by high values of the binding energies of the solvents in these two forms. The enthalpy of solution was found to be endothermic for all the forms which followed the order: Form O $>$ Form II $>$ Form III $>$ Form I > Form IV and is further related to the lattice energy suggesting Form II to be least crystalline. The solubility for Form II was found to be highest with maximum release rate in dissolution studies. The effectiveness of new polymorphic forms was confirmed by performing in vivo antimalarial activity against $P$. berghei infection. The studies have shown an increase in antimalarial activity of Form IV concluding a successful development of new polymorphic form.
\end{abstract}

Keywords: Quinine Sulphate; Enthalpy; Polymorphs; Solvates; Crystals

\section{Introduction}

Natural phytochemicals have always drawn great attention from clinicians owing to their multitude of actions. These molecules have demonstrated potential in the prevention and/or treatment of various diseases, such as cancer, arthritis, diabetes, hepatitis and many more [1,2]. However, the majority of phytochemicals suffer from problems such as poor water solubility and poor metabolic stability, which limit their use in the clinic [3]. A large number of potential molecules including alkaloids isolated from plants despite having significant therapeutic activity do not reach market because of the above mentioned drawbacks. At the same time there are a number of naturally occurring drugs which are used therapeutically but suffer from limitations of solubility, stability and pharmacokinetics thereby preventing their suitable dosage forms. Their intractability to medicinal chemists further hinders their use [4-8]. Moreover, the large size and complex structure of natural products sometimes make them susceptible to crystallize into different crystal forms for traditionally difficult targets, such as proteins.

\footnotetext{
"Corresponding author.
}

Besides this, many of them are sensitive to external agents such as air, light, moisture, oxidative enzymes which constitute a serious problem for their bioavailability and formulation [9-13]. Quinine sulphate is one such alkaloid which requires extensive study as to improve its physicochemical parameters and render it much favourable for clinical application. One of the approaches is to prepare its alternate solid forms to generate a suitable form with improved solubility and stability $[14,15]$.

Thus this paper deals with the identification and characterization of polymorphic forms of dihydrate sulphate salt of quinine alkaloid. It is widely used drug not only as antimalarial but has also been used as a muscle relaxant. Though not much literature is available on the drug, not much work has been reported on its polymorphic forms except one recent patent [16]. Different analytical techniques such as differential scanning calorimetry (DSC), thermogravimetric analysis (TGA), X-ray powder diffractrometry (XRPD), fourier transform infrared spectroscopy (FT-IR), scanning electron microscopy (SEM), solution calorimetry, solubility and dissolution studies have been used to identify and characterize the various forms. The various forms have been subjected to antimalarial 
activity.

\section{Materials and Methods}

\subsection{Materials}

Quinine sulfate was obtained from SD Fine Chemicals Pvt. Ltd. Mumbai, India and various analytical grade solvents; n-propanol, iso-butyl alcohol, n-pentanol and tertamyl alcohol were used for recrystallization. Sodium dihydrogen orthophosphate dihydrate, disodium hydrogen orthophosphate dihydrate used to prepare buffer solution were of analytical grade.

\subsection{Preparation of Polymorphs}

Different polymorphic forms of quinine sulphate were obtained by recrystallizing quinine sulphate from n-propanol, iso-butyl alcohol, n-pentanol and tert-amyl alcohol. Quinine sulphate was dissolved in minimum amount of solvent at a temperature just near the boiling point of the respective solvents. The solutions were slowly cooled to room temperature and kept for complete crystallization for a period of about 7 days. The crystals obtained were isolated by filtration through Buchner funnel and kept in glass vacuum desiccator jars to remove solvent and stored in air tight vials. The slow recrystallization of quinine sulphate from propanol gives Form I whereas isobutyl alcohol gives Form II. The Form III was obtained by recrystallization from pentanol while Form IV was crystallized from a solution in tert-amyl alcohol.

\subsection{Differential Scanning Calorimetry (DSC)}

DSC thermograms were obtained on DSC, Q20, TA instruments-Waters and LLC USA. The instrument was calibrated for temperature and heat flow accuracy using the melting of pure indium $\left(\mathrm{mp} 156.6^{\circ} \mathrm{C}\right.$ and $\Delta \mathrm{H}$ of 25.45 $\mathrm{J} \cdot \mathrm{g}^{-1}$ ). The temperature range was from $25^{\circ} \mathrm{C}-250^{\circ} \mathrm{C}$ with a heating rate of $2^{\circ} \mathrm{C}$ per minute.

\subsection{Thermal Gravimetic Analysis (TGA)}

The TGA scans were obtained on TGA, Mettler, Star ${ }^{\mathrm{e}}$ SW 9.00. TGA traces were recorded at heating rate of $10^{\circ} \mathrm{C}$ per minute under a nitrogen purge of $50 \mathrm{~mL}$. Samples with masses between $1-10 \mathrm{mg}$ were analyzed using aluminum pan. Mass loss (\%) was calculated based on the mass of original sample.

\subsection{X-Ray Powder Diffraction (XRPD)}

Powder diffraction patterns were recorded on an X-Ray diffractometer (XPERT-PRO, Netherlands, Holland) with $\mathrm{Cu}$ as tube anode. The diffractograms were recorded under following conditions: voltage $35 \mathrm{kV}, 20 \mathrm{~mA}$, angular range 5, divergence slit 10 , receiving slit $0.15 \mathrm{~mm}$.

\subsection{Fourier Transform Infrared Spectroscopy (FT-IR)}

The FT-IR spectra were obtained on Spectrum RXI, FTIR spectrometer, (Perkin Elmer, UK) over the range 400 $4000 \mathrm{~cm}^{-1}$. Dry $\mathrm{KBr}(50 \mathrm{mg})$ was finely ground in mortar and samples of drug and its modifications $(1-2 \mathrm{mg})$ were subsequently added and gently mixed in order to avoid trituration of the crystals. A manual press was used to form the pellets.

\subsection{Calorimetric Study}

Calorimetric studies were performed on microreaction calorimeter obtained from Thermal Hazards Technology, UK. Acetate buffer $\mathrm{pH} 3$ was used to determine the enthalpy of solution and the measurements were performed at $37^{\circ} \mathrm{C}$. The quinine sulphate and its polymorphic forms were studied in the acetate buffer $\mathrm{pH} 3$. The size of sample used in this study ranged from 1 to $10 \mathrm{mg}$ and was weighed (Sartorius Model CP225D) into a cylindrical glass tube covered with paraffin film on one side. This cylindrical tube was submerged into the ampoule containing the solvent. A plunger with a cap was put from the open end of the tube. The same solvent was put into the reference ampoule. These were put into the sample and reference holes until both rests on the base of the holes. The apparatus was maintained at constant temperature at $37^{\circ} \mathrm{C}\left( \pm 0.005^{\circ} \mathrm{C}\right)$. The paraffin film was shattered mechanically by means of plunger.

\subsection{Scanning Electron Microscopy}

A Joel JSM-6100 Scanning Electron Microscope was used to obtain photomicrographs of different forms. Samples were mounted on a metal stub with an adhesive and coated under vacuum with gold.

\subsection{Solubility Studies of Polymorphs of Quinine Sulphate}

The solubility studies of quinine sulphate along with its forms were performed by introducing an excess amount of samples in phosphate buffer $\mathrm{pH} 7.0$, which were shaken in water bath shaker (MSW-275 Macroscientific works, Delhi) at $25^{\circ} \mathrm{C}$ and $37^{\circ} \mathrm{C}$ for 24 hours. The samples were withdrawn at different intervals, filtered through $0.45 \mu \mathrm{m}$ membrane filter (Millipore) and analyzed fluorometrically using Hitachi fluorometer.

Concentration of the drug quinine sulphate was calculated using the formula:

Concentration of drug $=($ Area under curve $\times$ Dilution factor) 


\subsection{Evaluation of Antimalarial Activity of Quinine Sulphate and Its Polymorphs in Mice}

The antimalarial evaluation was done using method described by Andradea et al. [17]. Plasmodium berghei (NK 65) strain was used for in vivo evaluation of antimalarial activity in Lacca mice. The $P$. berghei strain was maintained in mice by intraperitoneal inoculation (i/p) of the infected blood. 4 - 5 weeks old Lacca mice $(25-30 \mathrm{~g})$ were procured and maintained in the Central animal house and were provided with standard pellet diet and water ad libidum. Experiments were performed as per guidelines of committee for the purpose of the control and supervision on experiments on animals (CPC-SEA). The experimental protocol was approved by Institutional Animal Ethics Committee (vide ref. no.: IAEC/97, dated24/3/2011).

\subsection{Experimental Design}

Animals were divided into 5 groups and each group comprised of 6 animals. These were treated with two times a day therapy $(6 \mathrm{mg} / \mathrm{kg})$ on 1 day of post inoculation (PI) for 7 days to monitor the efficacy and potency of prepared forms.

1) Control group - treated with $0.5 \%$ carboxymethyl cellulose (CMC) suspension;

2) Standard group - administered quinine sulphate Form $\mathrm{O}$ in $0.5 \%$ CMCsuspension;

3) Test group 1 -treated with Form I in $0.5 \% \mathrm{CMC}$ suspension;

4) Test group 2-treated with Form II in $0.5 \%$ CMC suspension;

5) Test group 3-treated with Form III complex in $0.5 \%$ CMC suspension;

6) Test group 4-treated with Form IV complex in $0.5 \% \mathrm{CMC}$ suspension.

\subsection{Preparation and Administration of Doses}

Quinine sulphate and its forms were suspended in $0.5 \%$ carboxymethyl cellulose (CMC). Each animal was treated with $100 \mu 1$ quinine sulphate and various forms prepared in the present study.

\subsection{Challenge of the Experiment Animals and Follow Up of the Experimental Animals}

All the mice belonging to control group were challenged with $P$. berghei infected RBCs i/p. After challenge, mean percent parasitaemia, percent activity of various forms of quinine sulphate along with animal survivality was monitored. Mean percent parasitaemia was calculated for each group at different interval of time (days).

Mean percent parasitaemia $=$ Infected RBCs/Total no. of RBCs $\times 100$.

\subsection{Percent Parasitaemia}

Percent parasitaemia was monitored on every alternate day for upto 30 days by tail blood smear, fixed in methanol and stained in Giemsa stain by counting at least 500 cells.

\section{Statistical Analysis}

The difference between multiple groups of dissolution efficiency data (DE $90 \mathrm{~min}$ ) was assessed by analysis of variance followed by Tukey's post test to determine the level of significance between different groups. Mean differences with $\mathrm{P}<0.05$ were considered to be significant.

Data was expressed as mean \pm SD and parasitaemia of the quinine sulphate and its forms were statistically assessed by one-way ANOVA followed by Tukey's test using Jandel sigma stat 2.0 version. Differences were considered significant at $\mathrm{P}<0.05$.

\section{Results and Discussion}

Various modifications of quinine sulphate obtained after recrystallization from different solvents showed them to be morphologically distinct forms. The difference in morphology was confirmed by studying the shape and appearance by scanning electron microscopy (Figure 1).

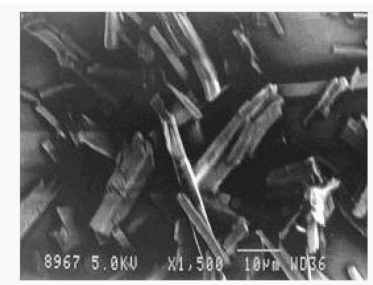

(a) Form 0

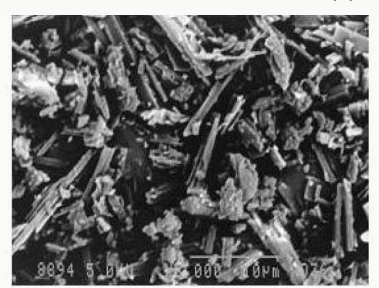

(b) Form I

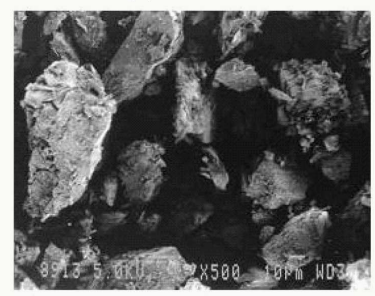

(d) Form III

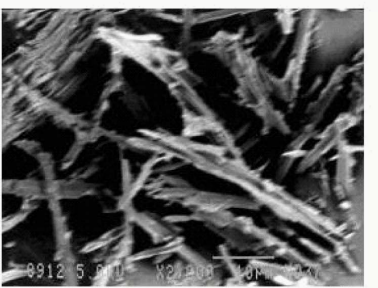

(c) Form II

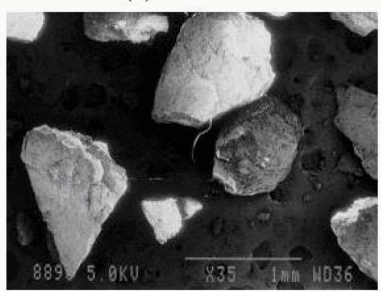

(e) Form IV
Figure 1. Scanning electron microscopy of quinine sulphate and its forms. 
Form O, commercial sample, showed acicular crystals while Form I crystallized out in prismatic shape. The crystals of Form II are also acicular crystals but different in dimensions. Form III was designated as anhedral crystals as no specific shape was observed. Form IV showed flaky crystals which were irregular in shape. These forms were then subjected to further physicochemical characterization.

Thermogravimetric analysis and differential scanning calorimetry.

TGA and DSC techniques, employed to quantitatively understand the thermal behavior, have been used to indicate the existence of different crystalline forms of quinine sulphate. Thermodynamic relationship between different phases, enantiotropic and monotropic transitions, transitions between different solvates and hydrates have also been determined by employing these techniques [18].

DSC scans of original sample (Form O) and its forms are shown in Figure 2. Form $\mathrm{O}$ first shows a broad endotherm which is followed by a single sharp melting endotherm at $209.8^{\circ} \mathrm{C}$ with enthalpy of fusion of $20.0 \mathrm{~J} / \mathrm{g}$ (Table 1). The broad peak corresponds to desolvation as suggested by TGA indicating commercial sample to be dehydrate (Figure 3).

In case of Form I and II it is seen that prior to fusion the thermal history is somewhat peculiar and intriguing. The Form I is characterized by one endotherm succeeded by an exothermic event, finally leading to sharp melting. No mass loss was observed in TGA in this region demonstrating these to be phase-phase transitions and ruling out the presence of solvatomorphism. In order to gain an understanding of the exotherm the form was heated in hot air oven to temperature in between the exotherm and melting endotherm to generate higher melting form. The DSC of the heat treated form showed a single sharp melting endotherm at $203.54^{\circ} \mathrm{C}$ different from that of initial sample indicating it to be a new polymorphic form. The form obtained by recrystallization is designated

Table 1. Thermal characteristics of different forms of quinine sulphate by differential scanning calorimetry.

\begin{tabular}{ccc}
\hline Sample & Melting point $\left({ }^{\circ} \mathrm{C}\right)$ & Enthalpy of fusion $(\mathbf{J} / \mathbf{g})$ \\
\hline Form O & 209.82 & 20.00 \\
Form $\mathrm{I}_{\mathrm{L}}$ & 154.4 & 1.79 \\
${\text { Form } \mathrm{I}_{\mathrm{H}}}$ & 203.5 & 48.0 \\
${\text { Form } \mathrm{II}_{\mathrm{L}}}$ & 144.7 & 58.2 \\
Form $\mathrm{II}_{\mathrm{H}}$ & 214.5 & 117.1 \\
Form III & 129.64 & 42.16 \\
Form III & 206.67 & 21.98 \\
Form IV & 103.29 & 15.57 \\
Form IV & 207.45 & 24.50 \\
\hline
\end{tabular}

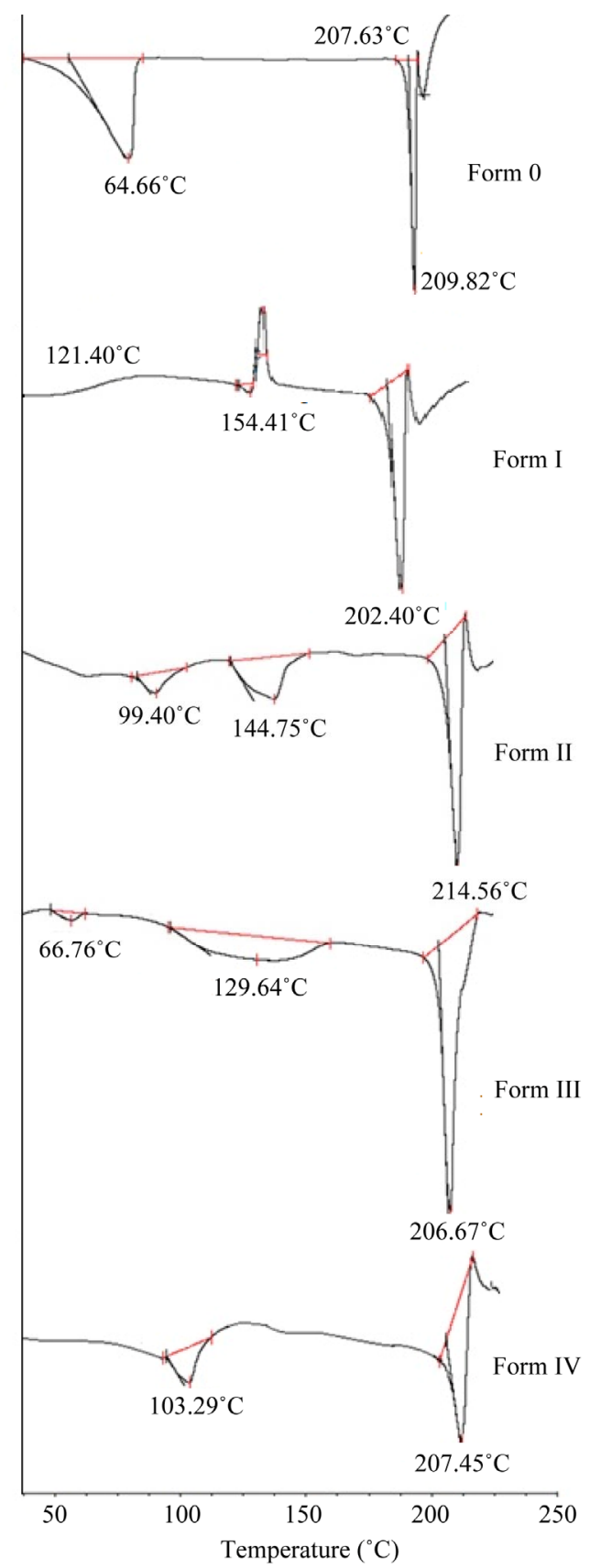

Figure 2. DSC plots of quinine sulphate and its forms.

Form $\mathrm{I}_{\mathrm{L}}$ which after solid-solid transition converts to a new form $\left(\right.$ Form $\left.\mathrm{I}_{\mathrm{H}}\right)$.

Form II shows a small endothermic peak at $141.7^{\circ} \mathrm{C}$ which is not associated with any mass loss in the TGA suggesting this endotherm to be a solid-solid transition and cannot be attributed to any inclusion of solvent in the crystal lattice. This low melting form $\left(\right.$ Form $\mathrm{II}_{\mathrm{L}}$ ) is transformed to a new form $\left(\right.$ Form $\left.\mathrm{II}_{\mathrm{H}}\right)$ which ultimately melts at $214.5^{\circ} \mathrm{C}$ with $117.1 \mathrm{~J} / \mathrm{g}$ enthalpy of fusion. Form $\mathrm{II}_{\mathrm{L}}$ was heated up to $160^{\circ} \mathrm{C}$ in an hot air oven and then cooled to produce Form $\mathrm{II}_{\mathrm{H}}$. The DSC scan of this heat treated 


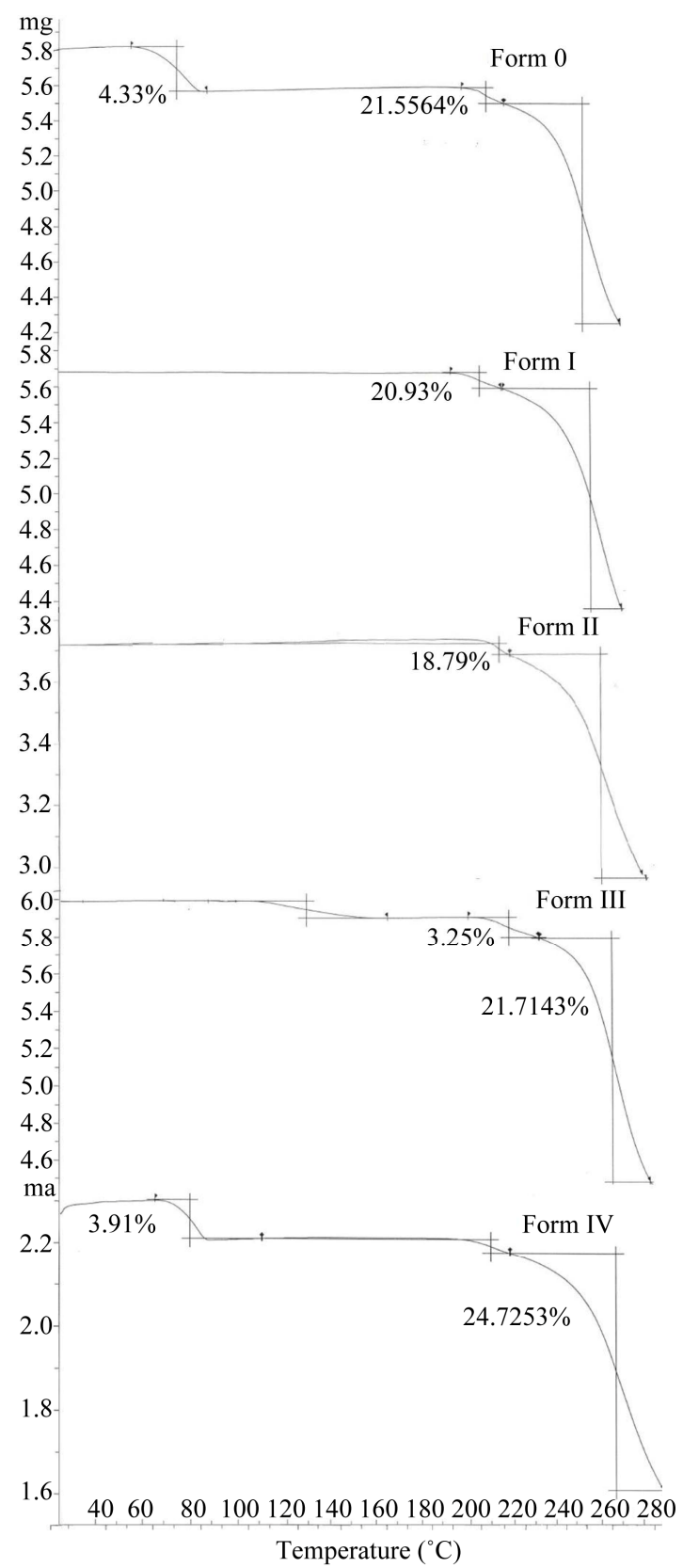

Figure 3. TGA plots of quinine sulphate and its forms.

form showed single melting endotherm at $214.5^{\circ} \mathrm{C}$ suggesting the generation of new polymorphic form after solid-solid transition.

Contrary to these two forms, in Form III (obtained from pentanol) broad endothermic peak at $129.6^{\circ} \mathrm{C}$ is associated with a mass loss of $5.3 \%$ in the TGA suggesting the presence of solvatomorphism. The position of the peak which is near to boiling point of pentanol $\left(138.0^{\circ} \mathrm{C}\right)$ and theoretical calculations reveal the removal of 0.5 mole of pentanol (theoretical 5.06\%) per mole of the quinine sulphate. This shows Form III to be pentanol solvate with 2:1 stoichiometry. The DSC thermogram predicts that after desolvation, Form III melts at $206.6^{\circ} \mathrm{C}$ with enthalpy of fusion $21.9 \mathrm{~J} / \mathrm{g}$ suggesting its conversion to Form O (Figure 4).

Form IV obtained from tert-amyl alcohol also showed a broad endothermic peak at $103.2^{\circ} \mathrm{C}$ in DSC and a corresponding mass loss of $3.9 \%$ (calculated at $5.0 \%$ ) in TGA. This corresponds to the removal of 0.5 mole of tert-amyl alcohol per mole of quinine sulphate. Thus Form IV is tert-amyl alcohol solvate of quinine sulphate with 2:1 stoichiometry. After the desolvation an exotherm between the desolvation endotherm and the melting endotherm appears which shows that once the solvent leaves, the lattice of the drug molecule reorganizes itself and revert back to original form as the melting temperature and enthalpy of fusion are similar to that of Form O.

Form III and IV which are solvatomorphic forms of quinine sulphate, were heated up to $170^{\circ} \mathrm{C}$ and $120^{\circ} \mathrm{C}$ respectively in a hot air oven to generate their corresponding desolvated forms (Form $\mathrm{III}_{\mathrm{des}}$ and Form $\mathrm{IV}_{\mathrm{des}}$ ). The

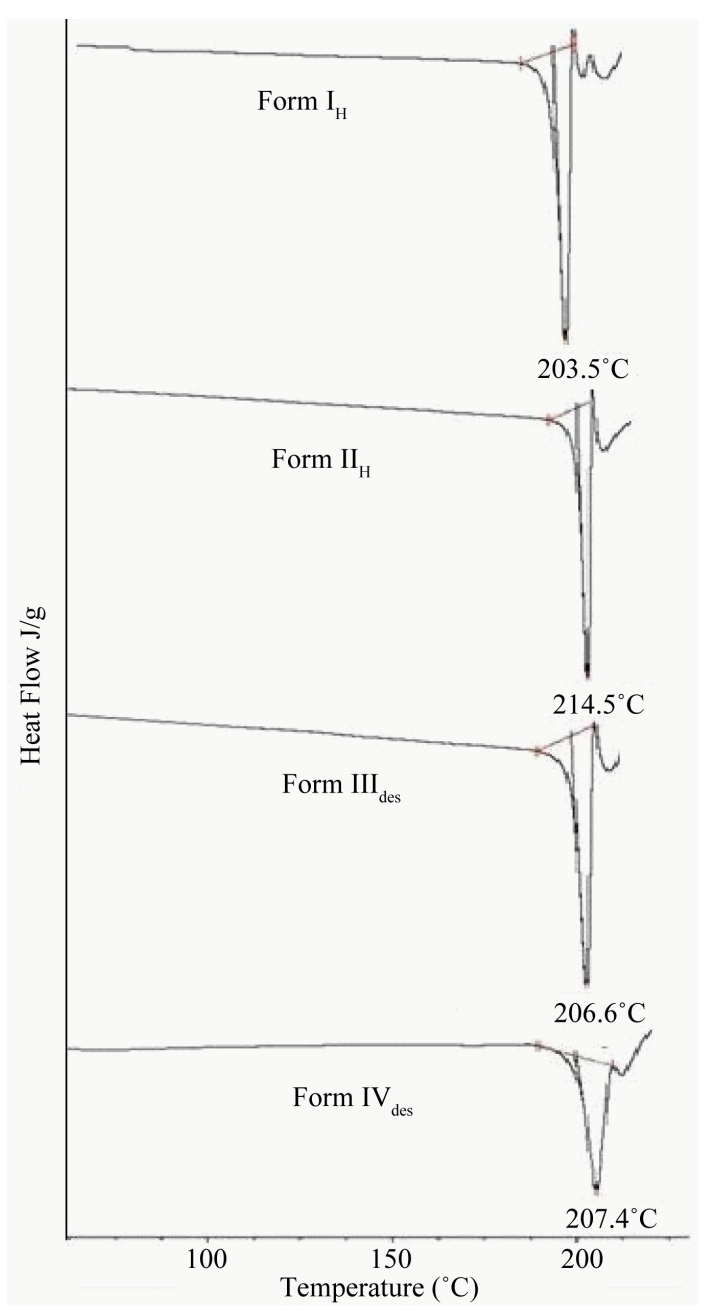

Figure 4. DSC plots of heat treated and desolvated samples of (a) Form $\mathrm{I}_{\mathrm{H}}$; (b) Form $\mathrm{II}_{\mathrm{H}}$; (c) Form $\mathrm{III}_{\text {des }}$ and (d) Form IV $\mathbf{d e s}$. 
DSC thermogram of desolvated forms shows the forms to be melting at $206.6^{\circ} \mathrm{C}$ and $207.5^{\circ} \mathrm{C}$ respectively which is similar to Form $\mathrm{O}$ indicating their conversion to Form $\mathrm{O}$ after desolvation (Figure 4).

\subsection{Thermodynamic Relationship between Polymorphic Forms}

In terms of stability, determination of whether the forms are monotropic or enantiotropic is of considerable benefit. The low melting and high melting Form $\mathrm{I}$ is found to be monotropically related with each other according to the Burger's heat of fusion rule. However, this rule cannot be applied to Form II as the first endotherm is not melting but solid-solid transition indicating this polymorphic pair to be enantiotropically related. Form $\mathrm{O}$ and $\mathrm{I}_{\mathrm{L}}$ are monotropically related while Form $\mathrm{O}$ is enantiotropically related to Form $\mathrm{I}_{\mathrm{H}}$. However, Form $\mathrm{O}$ is enantiotropically related to Form $\mathrm{II}_{\mathrm{L}}$ and monotropically related to Form $\mathrm{II}_{\mathrm{H}}$.

\subsection{Binding Energy of Solvents in Solvatomorphs}

The binding energies $[19,20]$ for the solvents in both the solvates have been calculated by the equation:

$$
\Delta \mathrm{H}_{\mathrm{S}}=\left[\left(\Delta \mathrm{H}_{\mathrm{Sexp}} \times 100\right) / \Delta \mathrm{m}_{\mathrm{S}} \%\right] \times \mathrm{M}_{\mathrm{S}}
$$

where $\Delta \mathrm{H}_{\mathrm{S}}\left(\mathrm{J} \cdot \mathrm{mol}^{-1}\right)$ is the enthalpy of desolvation (or binding energy) per mole of the bound solvent, $\Delta H_{\text {Sexp }}$ $\left(\mathrm{J} \cdot \mathrm{g}^{-1}\right)$ is the enthalpy of desolvation per $\mathrm{g}$ of the solvate, $\Delta \mathrm{m}_{\mathrm{S}} \%$ is the percentage mass loss, $\mathrm{M}_{\mathrm{S}}$ is the molecular mass of the solvent.

The comparison of $\Delta \mathrm{H}_{\mathrm{S}}$ values with the enthalpy of vaporization for the pure solvents reveal that in both the solvates the binding energy is higher than the enthalpy of vaporization suggesting that the solvent molecules are strongly bound in the host lattice (Table 2). The presence of tightly bound solvents is also evident from the desolvation temperatures in both the solvates, which are higher than the boiling point of pure solvent.

\subsection{X-Ray Powder Diffraction (XRPD)}

$\mathrm{X}$-ray powder diffractograms show distinct differences in the position of the peaks of various forms clearly indicating different crystal lattices (Figure 5). The XRPD pattern of Form $\mathrm{O}$ showed characteristic peaks at $2 \theta=$ $6.19^{\circ}, 9.42^{\circ}, 14.20^{\circ}, 16.20^{\circ}, 17.47^{\circ}, 18.50^{\circ}, 19.45^{\circ}$, $22.20^{\circ}, 25.50^{\circ}, 26.00^{\circ}, 27.30^{\circ}, 27.53^{\circ}$ and $30.5^{\circ}$. Comparison of the XRPD patterns of heat untreated samples of Form I, II, III and IV with that of Form O revealed the appearance as well as disappearance of few peaks supporting the change in crystal lattice. In XRPD of Form I, a few new peaks at $7.5^{\circ}, 8.20^{\circ}, 8.95^{\circ}, 14.95^{\circ}, 15.10^{\circ}$, $16.76^{\circ}$ and $20.20^{\circ}$ appeared whereas the characteristic peaks at $16.20^{\circ}, 27.30^{\circ}$ and $27.50^{\circ}$ were absent as compared to Form $\mathrm{O}$ indicating formation of a new phase. Similarly, a few new peaks at $10.8^{\circ}$ and $11.20^{\circ}$ appeared in Form II whereas peak at $18.50^{\circ}$ was absent. Position of these new peaks in Form I and Form II indicated these to be new forms.

Similarly, peaks at $12.50^{\circ}, 13.04^{\circ}, 14.51^{\circ}, 21.10^{\circ}$, $23.50^{\circ}, 24.40^{\circ}$ and $28.60^{\circ}$ appeared in XRPD pattern of Form III while Form IV showed newer characteristic peaks of significance at $8.20^{\circ}$ and absence of peak at $26.0^{\circ}$ suggested existence of new crystalline phases.

To follow the solid state transitions in Form I and II, as observed in DSC, the XRPD patterns were collected after heating these forms as discussed in the previous section. The relevant result reported in Figure 6 clearly evidenced a remarkable structural rearrangement taking place between Form $\mathrm{I}_{\mathrm{L}}$ and $\mathrm{II}_{\mathrm{L}}$. Existence of this new phase was supplemented by appearance of new peaks at $7.31^{\circ}, 8.05^{\circ}, 12.37^{\circ}, 13.20^{\circ}, 13.90^{\circ}$ and $18.41^{\circ}$ in Form $\mathrm{I}_{\mathrm{H}}$ and at $7.85^{\circ}, 8.59^{\circ}, 17.74^{\circ}, 17.97^{\circ}$ and $22.08^{\circ}$ in Form $\mathrm{II}_{\mathrm{H}}$. The XRPD of desolvated Form III and IV were found to be similar to Form $\mathrm{O}$ confirming the reconversion of the solvate to original lattice.

Quinine sulphate is well established drug but no data has been reported on its polymorphic forms except one patent in 2008 (16). However, the direct comparison of our results could not be made as the solvent system and other experimental conditions are different. The observation that the forms prepared in the present study and those in the literature are quite different is further supplemented by the differences in the XRPD patterns of all these forms.

Table 2. Thermal characteristics of Form O, III and IV of quinine sulphate by differential scanning calorimetry and thermogravimetric analysis.

\begin{tabular}{cccccccccc}
\hline Sample & $\begin{array}{c}\text { Boiling point } \\
\text { of solvent }{ }^{\circ} \mathrm{C}\end{array}$ & $\begin{array}{c}\text { Temperature of } \\
\text { desolvation }\left({ }^{\circ} \mathrm{C}\right)\end{array}$ & $\begin{array}{c}\text { Enthalpy of } \\
\text { desolvation } \\
(\mathrm{J} / \mathrm{g})\end{array}$ & $\begin{array}{c}\text { Temperature of } \\
\text { melting }\left({ }^{\circ} \mathrm{C}\right)\end{array}$ & $\begin{array}{c}\text { Enthalpy of } \\
\text { melting }(\mathrm{J} / \mathrm{g})\end{array}$ & $\begin{array}{c}\text { \% Mass } \\
\text { Calculated }\end{array}$ & $\begin{array}{c}\text { Experimental } \\
\text { lolue }\end{array}$ & $\begin{array}{c}\text { Enthalpy of } \\
\text { binding } \\
(\mathrm{kJ} / \mathrm{mole})\end{array}$ & $\begin{array}{c}\text { Enthalpy of } \\
\text { vaporization of } \\
\text { pure solvent } \\
(\mathrm{kJ} / \mathrm{mole})\end{array}$ \\
\hline Form O & 100 & 84.6 & 62.7 & 209.8 & 20.0 & - & - \\
Form III & 138 & 129.6 & 42.2 & 206.7 & 69.9 & 5.06 & 5.3 \\
Form IV & 102 & 103.3 & 15.6 & 207.5 & 44.5 & 5.05 & 3.0 \\
\hline
\end{tabular}






Figure 5. XRPD pattern of quinine sulphate and its forms.

\subsection{Fourier Transform Infrared Spectroscopy}

All the forms were identified and assigned by their IR spectra. Some of the characteristic frequencies are given in Table 3.

The -OH stretch in original sample shifted to 3219.1 and $3293.7 \mathrm{~cm}^{-1}$ in Form I and Form II respectively whereas the aromatic $\mathrm{C}=\mathrm{C}$ stretch shifted to 1515.3 and $1509.3 \mathrm{~cm}^{-1}$ in Form I and II respectively. The -C-O stretch shifted to $1248.9 \mathrm{~cm}^{-1}$ in Form I and $1238.1 \mathrm{~cm}^{-1}$ in Form II. Similarly, the C-N bend also showed a marked shift to $1074.4 \mathrm{~cm}^{-1}$ for Form I and to $1088.7 \mathrm{~cm}^{-1}$ for Form II. The above changes though small but are significant and well reproducible (Table 3).

As expected the pentanolate and tert-amyl alcholate showed characteristic and broad bands in the -OH stretch range because of incorporation of solvent molecules (pen-

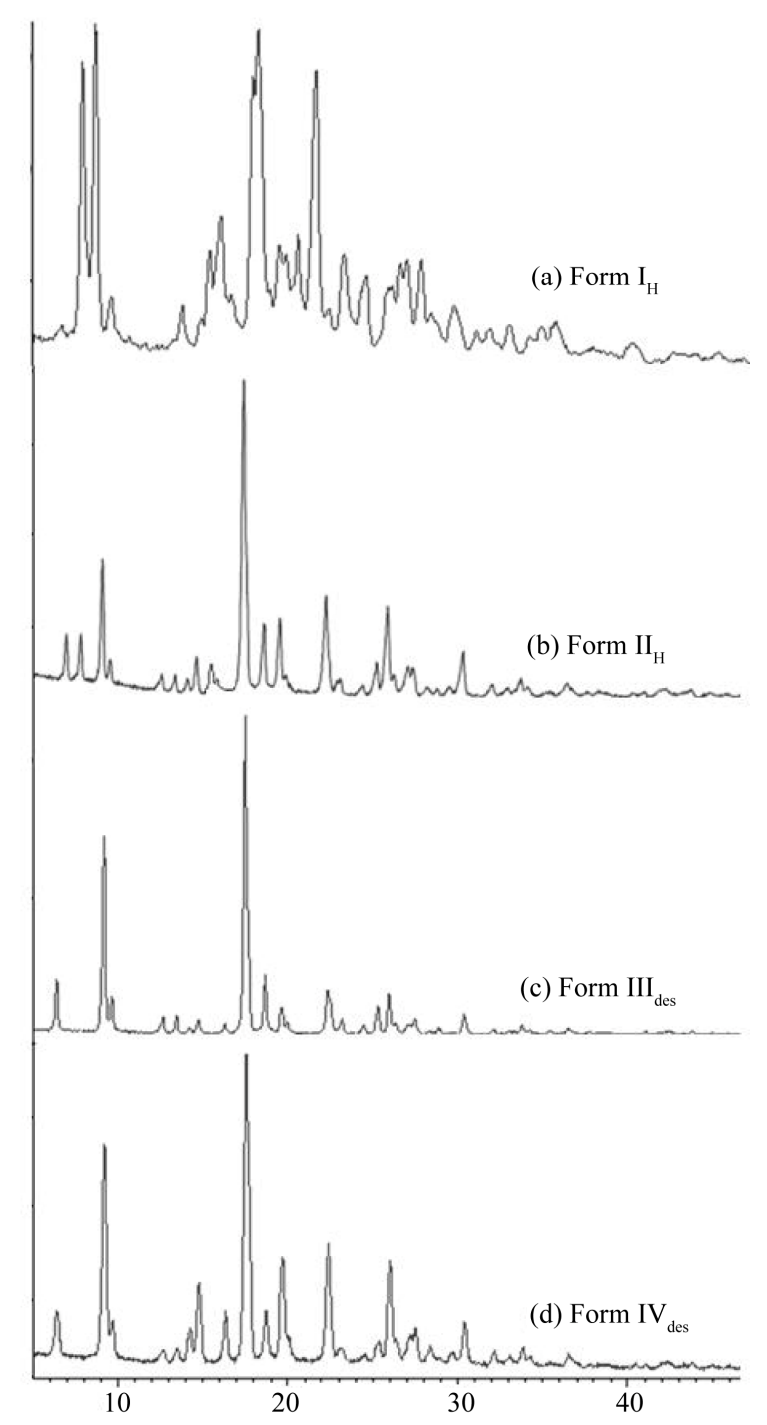

Figure 6. XRPD pattern of (a) Form $I_{H}$; (b) Form $I_{H}$; (c) Form III $_{\text {des }}$ and (d) Form IV $_{\text {des }}$ of quinine sulphate.

tanol in Form III and tert-amyl alcohol in Form IV) in their crystal lattice. The position of -OH stretch shifted to a lower wavelength in both Form III and IV $\left(3201.1 \mathrm{~cm}^{-1}\right.$ in Form III and $3210.4 \mathrm{~cm}^{-1}$ in Form IV) indicating increased H-bonding when the alcohols are present in the lattice. The aromatic $\mathrm{C}=\mathrm{C}$ stretch shifted to $1508.0 \mathrm{~cm}^{-1}$ while $\mathrm{C}-\mathrm{O}$ stretch shifted to $1239.0 \mathrm{~cm}^{-1}$ in both the cases suggesting similar type of interaction of drug with solvent molecules.

\subsection{Enthalpy of Solution}

The energy difference of the crystal lattices were estimated from the difference in enthalpy of solution obtained by dissolution of quinine sulphate and its various forms in acetate buffer $\mathrm{pH} 3$ at $37^{\circ} \mathrm{C}$ [21]. All the forms showed endothermic behavior and the magnitude of en- 
Table 3. Significant FT-IR peaks of quinine sulphate and its forms.

\begin{tabular}{cccccc}
\hline & $\begin{array}{c}\mathrm{O}-\mathrm{H} \\
\text { stretch }\left(\mathrm{cm}^{-1}\right)\end{array}$ & $\begin{array}{c}\text { Alkene C=C } \\
\text { stretch }\left(\mathrm{cm}^{-1}\right)\end{array}$ & $\begin{array}{c}\text { Aromatic C=C stretch } \\
\left(\mathrm{cm}^{-1}\right)\end{array}$ & $\begin{array}{c}\mathrm{C}-\mathrm{O} \text { stretch } \\
\left(\mathrm{cm}^{-1}\right)\end{array}$ & $\begin{array}{c}\mathrm{C}-\mathrm{N} \text { bend } \\
\left(\mathrm{cm}^{-1}\right)\end{array}$ \\
\hline Form O & 3211.0 & 1619.0 & 1506.9 & 1237.7 & 1082.4 \\
Form I & 3219.1 & 1620.2 & 1515.3 & 1248.9 & 1074.5 \\
Form II & 3293.7 & 1620.5 & 1509.3 & 1238.1 & 1088.7 \\
Form III & 3201.1 & - & 1508.0 & 1239.0 & - \\
Form IV & 3210.4 & - & 1508.0 & 1239.0 & - \\
\hline
\end{tabular}

thalpy of solution followed the order: Form O $>$ Form II $>$ Form III $>$ Form I $>$ Form IV. As energy is required to break crystal lattice, the most crystalline form is expected to exhibit more endothermic behavior (Table 4).

The enthalpy of solution was also determined for the high melting forms $\mathrm{I}_{\mathrm{H}}$ and $\mathrm{II}_{\mathrm{H}}$. The molar enthalpy of solution was found to be more endothermic than their corresponding low melting forms. This was as a consequence of lattice energy being more in the higher melting stable crystal form.

\subsection{Solubility Studies}

The solubility studies are important because it gives an insight in which the different forms will behave in similar conditions in solution phase. The solubility behaviour of the different forms was studied in phosphate buffer $\mathrm{pH}$ 7.0 at $25^{\circ} \mathrm{C}$, and also at $37^{\circ} \mathrm{C}$.

The results in the Table 4 show that solubility followed the same trend as in the heat of solution. The most crystalline form was Form $\mathrm{O}$ as shown by its least solubility whereas Form IV showed maximum solubility and least crystalline behaviour.

\subsection{Estimation of Thermodynamic Parameters for Polymorphic Pairs}

The enthalpy of solution is important in understanding and estimating the transition temperatures for polymorphic pairs in pharmaceuticals. The solubility data along with the enthalpy of solution data (Table 5) is used to determine the transition temperature in the polymorphic pairs. The enthalpy of transition $\left(\Delta \mathrm{H}_{\mathrm{tr}}\right)$, free energy of transition $\left(\Delta \mathrm{G}_{\mathrm{tr}}\right)$ and entropy of transition $\left(\Delta \mathrm{S}_{\mathrm{tr}}\right)$ accompanying the transition of one form to another form were determined at $37^{\circ} \mathrm{C}$ using the following equations.

$$
\Delta \mathrm{H}_{\mathrm{tr}}=\Delta_{\text {sol }} \mathrm{H}_{\mathrm{L}}-\Delta_{\mathrm{sol}} \mathrm{H}_{\mathrm{H}}
$$

where, $\Delta_{\text {sol }} \mathrm{H}_{\mathrm{L}}$ is the enthalpy of solution of lower melting form and $\Delta_{\mathrm{sol}} \mathrm{H}_{\mathrm{H}}$ is the enthalpy of solution of higher melting form.

$$
\Delta \mathrm{G}_{\mathrm{tr}}=-\mathrm{RT} \ln \mathrm{S}_{\mathrm{L}} / \mathrm{S}_{\mathrm{H}}
$$

where, $\mathrm{S}_{\mathrm{L}}$ is the solubility of lower melting form and $\mathrm{S}_{\mathrm{H}}$ is the solubility of higher melting form.
Table 4. Molar enthalpy of solution and solubility of differrent forms of quinine sulphate.

\begin{tabular}{lccc}
\hline Sample & $\begin{array}{c}\text { Enthalpy of solution } \\
(\mathrm{kJ} / \mathrm{mol}) \text { at } 37^{\circ} \mathrm{C}\end{array}$ & \multicolumn{2}{c}{ Solubility $\left(\times 10^{-1} \mathrm{moles} / \mathrm{L}\right)$} \\
\cline { 3 - 4 } & 46.74 & 0.496 & 0.437 \\
\hline Form O & 21.18 & 0.523 & 0.483 \\
Form $\mathrm{I}_{\mathrm{L}}$ & 22.90 & 0.406 & 0.376 \\
${\text { Form } \mathrm{I}_{\mathrm{H}}}$ & 43.89 & 0.499 & 0.477 \\
Form $\mathrm{II}_{\mathrm{L}}$ & 45.81 & 0.413 & 0.398 \\
Form $\mathrm{II}_{\mathrm{H}}$ & 41.81 & 0.525 & 0.478 \\
Form III & 20.67 & 0.564 & 0.497 \\
Form IV & & & \\
\hline
\end{tabular}

Table 5. The enthalpy of transition $\left(\Delta \mathrm{H}_{\mathrm{tr}}\right)$, free energy of transition $\left(\Delta G_{\mathrm{tr}}\right)$, entropy of transition $\left(\Delta \mathrm{S}_{\mathrm{tr}}\right)$ and transition temperature $\left(T_{t}\right)$ of different polymorphic pairs at $37^{\circ} \mathrm{C}$.

\begin{tabular}{lccccc}
\hline $\begin{array}{l}\text { Polymorphic pair } \\
\text { \& Transition }\end{array}$ & $\begin{array}{c}\Delta \mathbf{H}_{\text {tr }} \\
((\mathbf{k J} / \mathbf{m o l})\end{array}$ & $\begin{array}{c}\Delta \mathbf{G}_{\text {tr }} \\
(\mathbf{k J} / \mathbf{m o l})\end{array}$ & $\boldsymbol{\Delta} \mathbf{S}_{\text {tr }}(\mathbf{J} / \mathbf{m o l})$ & $\mathbf{T t}(\mathbf{K})$ \\
\hline$\left(\mathrm{I}_{\mathrm{L}} / \mathrm{I}_{\mathrm{H}}\right)$ & $\mathrm{I}_{\mathrm{L}} \rightarrow \mathrm{I}_{\mathrm{H}}$ & -1.723 & -0.645 & -3.48 & 495.6 \\
$\left(\mathrm{II}_{\mathrm{L}} / \mathrm{II}_{\mathrm{H}}\right)$ & $\mathrm{II}_{\mathrm{L}} \rightarrow \mathrm{II}_{\mathrm{H}}$ & -1.927 & -0.466 & -4.71 & 409.0 \\
\hline
\end{tabular}

The entropy of transition between the two forms is calculated by the equation below:

$$
\Delta \mathrm{S}_{\mathrm{tr}}=\left(\Delta \mathrm{H}_{\mathrm{tr}}-\Delta \mathrm{G}_{\mathrm{tr}}\right) / \mathrm{T}
$$

At the transition temperature, $\mathrm{T}_{\mathrm{t}}$

$$
\Delta \mathrm{G}_{\mathrm{tr}}=0=\Delta \mathrm{H}_{\mathrm{tr}}-\mathrm{T}_{\mathrm{t}} \times \Delta \mathrm{S}_{\mathrm{tr}}
$$

Hence,

$$
\mathrm{T}_{\mathrm{t}}=\Delta \mathrm{H}_{\mathrm{tr}} / \Delta \mathrm{S}_{\mathrm{tr}}
$$

The numerical values of transition parameters are given in Table 5. The transition temperatures for the polymorphic transitions were also calculated using Equation (5). It is clear from Table 5 that the value of $\Delta \mathrm{H}_{\mathrm{tr}}$, $\Delta \mathrm{G}_{\mathrm{tr}}$ and $\Delta \mathrm{S}_{\mathrm{tr}}$ were negative for polymorphic pairs $\mathrm{I}_{\mathrm{L}} / \mathrm{I}_{\mathrm{H}}$ and $\mathrm{II}_{\mathrm{L}} / \mathrm{II}_{\mathrm{H}}$ suggesting that the transformations were enthalpically and entropically favoured. The transition temperature is higher than the melting of higher melting Form I indicating that the transition temperature is a hypothetic temperature and this fact corresponds to monotropic relationship between this pair of polymorphs. The transition temperature for lower melting Form II is lower 
Table 6. Antimalarial activity of the various forms of quinine sulphate against $P$. berghei infection in mice.

\begin{tabular}{ccccc}
\hline S. No. & Group & Treatment & Mean \% parasitaemi on 8 day PI & \% Mortality at 30 days $(\mathrm{n}=6)$ \\
\hline 1. & Control group & $0.5 \%$ CMC suspension & $45.56 \pm 3.8$ & 100.0 \\
2. & Standard group & Quinine sulphate $(6 \mathrm{mg} / \mathrm{kg})$ & $15.72 \pm 2.6$ & 50.0 \\
3. & Test group 1 & Form I & $4.17 \pm 0.32$ & 32.7 \\
4. & Test group 2 & Form II & $5.43 \pm 0.86$ & 32.7 \\
5. & Test group 3 & Form III & $4.32 \pm 0.20$ & 32.7 \\
6. & Test group 4 & Form IV & $2.45 \pm 0.43$ & 16.7 \\
\hline
\end{tabular}

${ }^{\mathrm{a}}$ Values expressed as mean $\pm \mathrm{SD}(\mathrm{n}=6)$; PI: post inoculation.

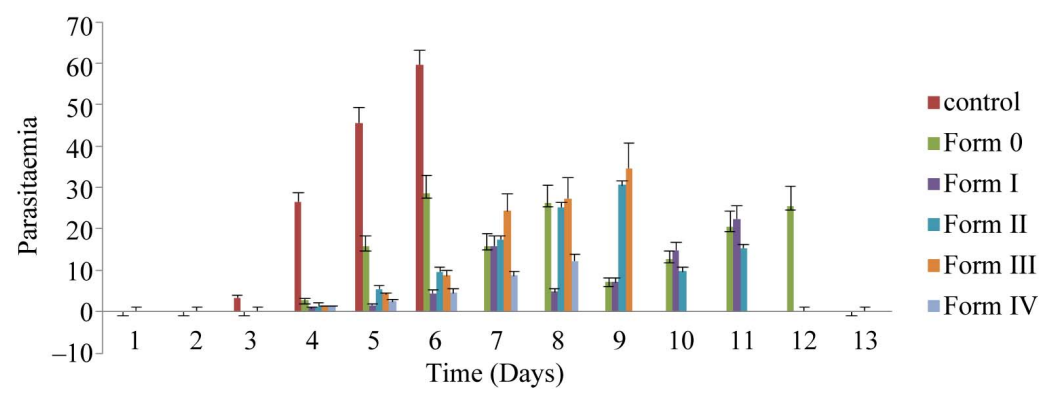

Figure 7. Mean percent parasitaemia of different forms of quinine sulphate.

than the melting of lower melting indicating this polymorphic pair to be enatiotropically related.

\subsection{Evaluation and Comparison of Pharmacological Antimalarial Activity of Quinine Sulphate and Its Forms}

The in vivo antimalarial activity and efficacy against $P$. berghei infection of quinine sulphate and its different forms was performed and the results are summarized in Table 6. It is clear from the table that Form $\mathrm{O}$ alone (standard group) is insufficient to prevent the mortality. The suspensions of the Form I, II, III and IV were administered to compare and differentiate them on the basis of their protective efficacy and potency. At the end of the treatment (day 8), when compared with control (45.56 \pm $3.78)$ (Figure 7) the Form $\mathrm{O}(15.72 \pm 2.65)$, Form I (4.17 $\pm 0.321)$, Form II $(5.43 \pm 0.86)$, Form III $(4.32 \pm 0.202)$ and Form IV $(2.45 \pm 0.43)$ showed significantly less $(\mathrm{P}<$ $0.001)$ mean percent parasitaemia. It was observed that percent mortality rate increased from $50 \%$ for Form $\mathrm{O}$ to $67.3 \%$ for Form I, II and III and to $83.3 \%$ in Form IV. ANOVA has also shown significant $(\mathrm{P}<0.05)$ antimalarial activity of all forms as compared to original quinine sulphate.

\section{Conclusion}

The recrystallization of commercial sample of quinine sulfate from different solvents and its solid state characterization shows the existence of two polymorphs and two solvatomorphs. The thermodynamic relationship among all the forms has been established from thermochemical parameters derived from DSC. The appearance of new phases is also suggested by XRPD and FTIR data. Enthalpy of solution determined to further differentiate the forms showed that Form IV obtained from tert-amyl alcohol exhibited least endothermic effect indicating its least crystalline nature. This form is also found to exhibit maximum solubility and dissolution rate. The percent mortality rate was found to decrease from 50\% in Form $\mathrm{O}$ to $16.7 \%$ in Form IV, the maximum of all the forms, suggesting a possibility for further development.

\section{REFERENCES}

[1] J. D. Newman and G. M. Cragg, "Natural Products as Sources of New Drugs over the Last 25 Years," Journal of Natural Products, Vol. 70, No. 3, 2007, pp. 461-477. doi:10.1021/np068054v

[2] J. Kelland, S. Y. Sharp and P. M. Rogers, "DT-Diaphorase Expression and Tumor Cell Sensitivity to 17Allylamino, 17-Demethoxygeldanamycin, an Inhibitor of Heat Shock Protein 90," Journal of National Cancer Institute, Vol. 91, No. 22, 1999, pp. 1940-1949. doi:10.1093/jnci/91.22.1940

[3] C. A. Lipinski, F. Lombardo, B. W. Dominy and P. J. Feeney, "Experimental and Computational Approaches to Estimate Solubility and Permeability in Drug Discovery and Development Settings," Advanced Drug Delivery Review, Vol. 46, No. 1-3, 2001, pp. 3-26. doi:10.1016/S0169-409X(00)00129-0

[4] M. R. Roberts and M. Wink, "Alkaloids," In: T. Acamovic, C. S. Stewart and T. W. Pennycott, Eds., Bio- 
chemistry, Ecology and Medical Applications, Plenum Press, New York, 1998.

[5] C. W. Evans, "Trease and Evans Pharmacognosy," 16th Edition, W. B. Saunders and Company Ltd., London, 2002, pp. 333-393.

[6] A. R. Battersby, "Research on Alkaloids in Retrospect and in Prospect," Tetrahedron, Vol. 14, No. 1-2, 1961, pp. 1-7. doi:10.1016/0040-4020(61)80082-3

[7] N. Khan and S. Aripov, "The Technological Classification of Alkaloids and Methods of Obtaining Them from Plant," Chemistry of Natural Compounds, Vol. 13, No. 6, 1984, pp. 624-634.

[8] D. J. Newman and G. M. Cragg, "Natural Products as Sources of New Drugs over the Last 25 Years," Journal of Natural Products, Vol. 70, No. 3, 2007, pp. 461-477. doi: $10.1021 / \mathrm{np} 068054 \mathrm{v}$

[9] L. M. Harwood and C. J. Moody, "Experimental Organic Chemistry: Principles and Practice," 4th Edition, Blackwell Scientific, Oxford, 2003, pp. 118-122.

[10] W. P. Jones and A. D. Kinghorn, "Extraction of Plant Secondary Metabolites," Natural Products Isolation, Vol. 20, No. 2, 2005, pp. 323-351.

[11] G. V. Burchianti, C. Marcello, F. De Andrade and R. D. Albuquerque, "Process for the Extraction and Purification of Alkaloids," U.S. Patent Number 5684155, 1996.

[12] R. J. Parry, "Biosynthesis of the Cinchona Alkaloids: Middle Stages of the Pathway," Chemical Communications, Vol. 30, 1971, pp. 123-130.

[13] D. J. Berrisford, C. Bolm and K. B. Sharpless, "LigandAccelerated Catalysis," Angewandte Chemie International Edition, Vol. 34, No. 10, 1995, pp. 1059-1070. doi:10.1002/anie.199510591

[14] J. K. Haleblian, "Characterization of Habits and Crystal- line Modification of Solids and Their Pharmaceutical Applications," Journal of Pharmaceutical Sciences, Vol. 64, No. 8, 1975, pp. 1269-1288. doi:10.1002/jps.2600640805

[15] J. Bernstein, "Polymorphism in Molecular Crystals," Oxford University Press, Oxford, 2002.

[16] K. R. Nielsen, T. Sun, K. Lorimer, K. W. Meyer and S. Watson, "Qunine Sulphate Polymorphs, Process of Preparing, Compositions and Uses Thereof," US AA61K31439F1, 2009.

[17] A. A. Andradea, F. P. Varottia, I. O. Freitasa, M. V. N. Souzab, T. R. A. Vasconcelosb, N. Boechatb, A. U. Krettlia, "Enhanced Activity of Mefloquine and Artesunic Acid against Plasmodium falciparum in vitro and $P$. berghei in Mice by Combination with Ciprofloxacin," European Journal of Pharmacology, Vol. 558, No. 1-3, 2007, pp. 194-198. doi:10.1016/j.ejphar.2006.11.061

[18] D. Giron, "Thermal Analysis and Calorimetric Methods in the Characterization of Polymorphs and Solvates," Thermochim Acta, Vol. 248, 1995, pp. 1-59. doi:10.1016/0040-6031(94)01953-E

[19] A. Othman, J. S. O. Evans, I. R. Evans and R. K. Harris, "Structural Study of Polymorphs and Solvates of Finasteride," Journal of Pharmaceutical Sciences, Vol. 96, No. 5, 2007, pp. 1380-1397. doi:10.1002/jps.20940

[20] M. R. Caira, G. Bettinetti, M. Sorrenti and L. Catenacci, "Relationships between Structural and Thermal Properties of Anhydrous and Solvated Crystalline Forms of Brodimoprim," Journal of Pharmaceutical Sciences, Vol. 96, No. 5, 2007, pp. 996-1007. doi:10.1002/jps.20934

[21] R. Chadha, P. Arora, A. Saini and D. V. S. Jain, "Solvated Crystalline Forms of Nevirapine: Thermoanalytical and Spectroscopic Studies," AAPS Pharm Sci Tech, Vol. 11, No. 3, 2010, pp. 1328-1339. doi:10.1208/s12249-010-9511-Z 